\title{
Evaluation of autogenous tooth transplantation for replacement of the missing or unrestorable mandibular molar tooth
}

\author{
Wahiduj Jaman and Shohda Khatun
}

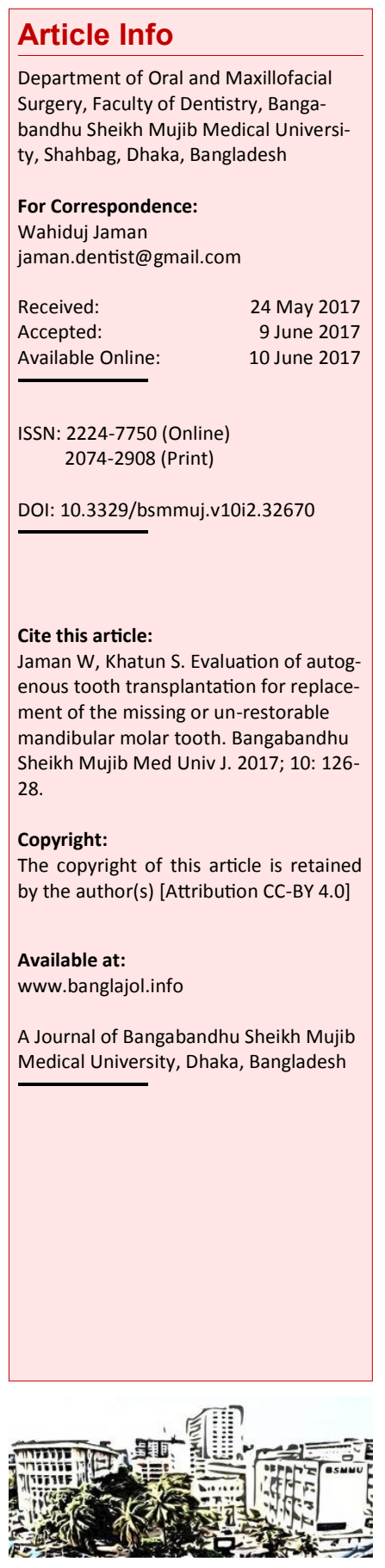

\section{Abstract}

This study was undertaken to evaluate the functional and occlusal stability of autogenous tooth transplantation. A total of 30 patients were included. Among them, 21 participants received transplanted first molar and the remaining 9 received transplanted second molar. In all the cases, donor tooth were third molar. In each participant, extraction of unrestorable first or second molar tooth was performed which was then replaced by atrumatic extracted third molar tooth. Each third molar tooth was placed in the recipient extracted socket, followed by the evaluation of the occlusion and then stabilized with arch bar and ligature wire. Clinical follow-up evaluation was performed at 15 days, 3 and 12 months in respect to occlusal stability, tooth mobility and periodontal status. It was found that 22 transplanted tooth were successful and the remaining 8 tooth need long-term observation for the final outcome, which was statistically significant. It can be concluded that the autogenous tooth transplantation can replace missing tooth to ensure the preservation of function, aesthetic and to prevent bone resorption of the missing area of the jaw, which can lead to exceptional esthetic and functional outcome.

\section{Introduction}

The autogenous tooth transplantation is the transfer of a tooth from one position to another in the same individual. It was first well documented in 1954.1 The principle of this technique is still followed. This could involve the transfer of an impacted or ectopic positioned tooth into extracted site or surgically prepared socket. Successful tooth transplantation depends upon the vitality of remaining periodontal ligament cells in the donor roots, the shape and the site of the recipient socket and the vascularity of the recipient bed.2 It was suggested that, tooth should be transplanted to the sockets with regenerative tissue which may reduce the root resorption following transplantation. $\frac{3}{-}$

Autotransplantation has a low procedural cost compared to that of osseointegrated implants since it is performed in a single stage and no prosthesis is required. $\underline{4}$ However, careful case selection and treatment planning are essential requisites for successful autotransplantation and the recipient site must be healthy and of adequate size to receive the transplant. Therefore, it is important to prepare the recipient site before the transplant is made available and transplantation completed with endodontic therapy. 5

Freshly extracted recipient sockets demonstrate higher success rate comparing to artificially drilled once due to contributions of the progenitors periodontal ligament cell on the recipient fresh extracted sockets.

The most important criteria for success involving the recipient site is adequately body support in all the dimensions with adequate attachment of keratinized tissue to allow for stabilization of the transplanted tooth.6, 7 The extra-alveolar time exceeding $18 \mathrm{~min}$ of a donor's tooth affected the survival rate of periodontal ligament cells significantly. In this regard, the extra-oral time of 10-11 $\mathrm{min}$ in this case seems to be the safe margin. $.5,6$ Ideal recipient site should have sufficient alveolar bone support in all the dimensions, an appropriate amount of attached keratinized tissue, and no inflammation.

The aim of this study was, therefore, to evaluate the functional and occlusal stability of autogenous tooth transplantation for the replacement of missing or unrestorable mandibular molar tooth, in vivo.

\section{Materials and Methods}

This study was conducted among the 30 patients from March 2014 to February 2016. All participants had impacted or ectopic positioned 
of the mandibular third molar. Participant who had either congenitally missing or early loss or unrestorable first or second molar tooth due to the large carious lesion was included. Each participant received extraction of unrestorable first or second molar tooth, which was later replaced by atrumatic extraction of the third molar tooth.

A total of 30 participants were included of which 18 were female and 12 were male. Twenty-one participants received the transplanted first molar and the remaining 9 participants received the transplanted second molar.

\section{Procedures}

The sequence of autogenous tooth transplantation includes clinical, radiographic examination, diagnosis, treatment planning, surgical treatment, endodontic treatment, restorative treatment and maintenance. With all aseptic precaution, after sufficient anesthesia, the diseased first or second mandibular molar tooth at the recipient site was extracted and the surgical preparation of the recipient site was performed. The recipient site was prepared adequately to the estimated size needed for the donor's tooth. The donor's third molar tooth was then carefully removed to ensure minimal trauma to the periodontal ligament and preserved carefully (Figure 1). The recipient socket was curate and irrigated by normal saline with gentamicin antibiotic solution. The donor tooth was then placed into the recipient socket with minimal delay between extraction and transplantation. If further adjustment of the recipient socket was required, then the donor tooth was stored in the original socket or normal saline. Once the transplantation was completed, occlusion was checked. The tooth was placed in slight infraocclusion to avoid occlusion trauma to the next few months. After proper positioning of the tooth, it was stabilized with the adjacent tooth by splinting for 2 weeks. Splinting was done by an arch bar with 26 gaze stainless steel ligature wire. Finally, donor socket was closed by 4-0 silk. The root canal therapy of transplanted tooth was performed after 2 months.

\section{Evaluation}

Three times follow-up evaluations were performed as the first, second and third visit at 15 days, 3 months and 12 months, respectively. In each followup period, the occlusal status was checked as favorable and unfavorable occlusion. Tooth mobility was investigated according to the Millers classification,,$\underline{8}$ and periodontal status was evaluated by Community Periodontal Index (CPI).

\section{Results}

Regarding occlusion status, it was found that 23 transplanted tooth out of 30 had favorable occlusion at the first and second follow-up period (Table I). Furthermore, at third follow-up period, 22 teeth had favorable occlusion, which was statistically significant. There was deviation of occlusion in one patient from the first to the second follow-up visit due to occlusal trauma.

The results of tooth mobility revealed that at 15 days, Class 0 was in 7 tooth. After 3 months, Class 0 was in 22 teeth. So, the mean mobility of transplanted teeth after the first and second visits was

\begin{tabular}{|c|c|c|c|}
\hline \multicolumn{4}{|c|}{ Table I } \\
\hline \multicolumn{4}{|c|}{ Results in follow-up visits } \\
\hline \multirow[t]{2}{*}{ Evaluation } & \multicolumn{3}{|c|}{ Follow-up } \\
\hline & $\begin{array}{r}\text { First } \\
(n=30)\end{array}$ & $\begin{array}{l}\text { Second } \\
(n=30)\end{array}$ & $\begin{array}{r}\text { Third } \\
(n=30)\end{array}$ \\
\hline \multicolumn{4}{|c|}{ Occlusal status } \\
\hline Favorable & 23 & 23 & 22 \\
\hline Unfavorable & 7 & 7 & 8 \\
\hline \multicolumn{4}{|c|}{ Tooth mobility by class } \\
\hline 0 & 7 & 22 & 22 \\
\hline I & 21 & 3 & 0 \\
\hline II & 2 & 4 & 3 \\
\hline III & 0 & 1 & 5 \\
\hline \multicolumn{4}{|c|}{ Periodontal score } \\
\hline 0 & 17 & 22 & 22 \\
\hline 1 & 5 & 1 & 0 \\
\hline 2 & 3 & 1 & 0 \\
\hline 3 & 5 & 5 & 0 \\
\hline 4 & 0 & 1 & 6 \\
\hline
\end{tabular}
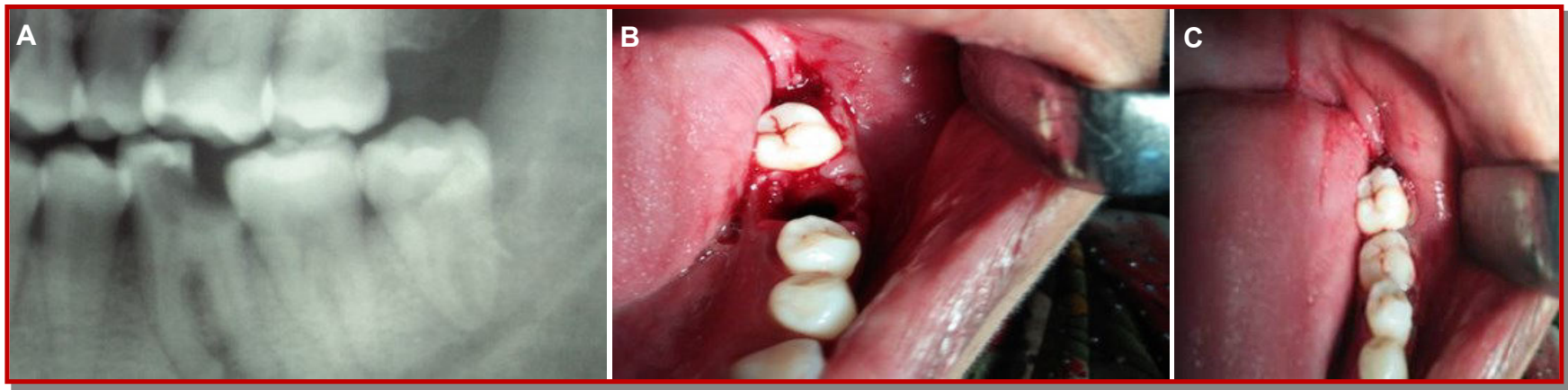

Figure 1: Representative photographs of a case of autogenous tooth tranpaltation. Pre-operative X-Ray (A), per-operative (B) and postoperative (C) photographs 
significant $(\mathrm{p}=0.001)$. After 12 months, Class 0 was in 22 teeth. So, the mean mobility of teeth after 12 months was also significant $(p=0.01)$ between the first and third follow-up visits.

The periodontal condition of each participant showed that at 15 days, the Score 0 was in 17 teeth. At 12 months, Score 0 was in 22 teeth. The result between the first and third visits was satisfactory significant $(p=0.003)$.

\section{Discussion}

Three parameters such as occlusal status, mobility and periodontal status of transplanted tooth were evaluated. The occlusal status was favorable 22 tooth at 12 months. A study shows that postoperative centric occlusion in the subjects who recorded $82 \%$ favorable and $18 \%$ are unfavorable. 9

The mobility of transplanted teeth was evaluated postoperatively in various follow-up visits. At final follow-up, it was observed that, Class 0 was 22 tooth.

The postoperative periodontal status was observed by CPI Index. At final follow-up visit (12 months), it was observed that, CPI Index Score 0 was 22 tooth. After evaluation of all parameters, the success rate of this study was $22(73.3 \%)$ tooth at the final visit.

The literature reports excellent success rates following autogenous tooth transplantation when the appropriate protocol is followed, found 95\% and $98 \%$ long-term survival rates for incomplete and complete root formation of 370 transplanted premolars and molars observed over a period of 13 years, early endodontic treatment has been proposed to prevent passage of degradation products and toxins from non-vital pulp tissue into the surroundding tissues, through the apical foramen, accessory canals, or dentinal tubules.? Endodontic treatment may thus facilitate arrest of the resorption process. 10 In a study observed that, 28 premolars with complete root formation, treated endodontically 4 weeks after transplantation, had a 5-year survival rate of $98 \% .11$ A study performed auto transplantation in 215 patients with a mean follow-up of 4.8 years and reported an overall success rate of $81 \%$ and a $100 \%$ success rate of premolars autotransplanted to the maxillary incisor region. $\underline{12}$ Similar findings were reported another study, who obtained a success rate of $84 \%$ in a case series.

If the transplanted tooth develops root resorption, this usually occurs within the late first year after surgery. The incidence of root resorption can be decreased with atrumatic extraction of donor tooth immediate transfer to the recipient site to minimize the risk of injury to the periodontal ligament. $\underline{13}$

\section{Conclusion}

The autogenous tooth transplantation can replace missing teeth to ensure the preservation of function, aesthetic and to prevent bone resorption of missing area of jaw, which can lead to exceptional esthetic and functional outcome.

\section{References}

1. Hale ML. Autogenous transplants. Oral Surg Oral Med Oral Pathol. 1956; 9: 76-83

2. Kim E, Jung JY, Cha IH, Kum KY, Lee SJ. Evaluation of the prognosis and causes of failure in 182 cases of autogenous tooth transplantation. Oral Surg Oral Med Oral Pathol Oral Radiol Endod. 2005; 100: 11219.

3. Akiyama Y, Fukuda H, Hashimoto K. A clinical and radiographic study of 25 autotransplanted third molars. J Oral Rehabil. 1998; 25: 640-44.

4. Chawla R, Fanibunda U, Hegda V. Autotransplantation the best implant for a missing tooth is a natural tooth. IOSR-JDMS. 2015; 14: 8-12.

5. Andreasen JO, Paulsen HU, Yu Z, Schwartz O. A long-term study of 370 autotransplanted premolars. Part III. Periodontal healing subsequent to transplantation. Eur J Orthod. 1990; 12: 25-37.

6. Cameron ML. Clokio, Deirdre M. You, Chano L. Autogenous tooth transplantation: An alternative to dental implant placement? J Can Dent Assoc. 2011; 67: 92-96.

7. Chugh A, Aggarwal, Chugh VK, Wadwa P, Kohhi M. Autogenous tooth transplantation as a treatment option. Int Clin Pediatr Dent. 2015; 5: 87-92.

8. Miller HM. Transplantation and replantation of teeth. Oral Surg. 1956; 9: 84.

9. Kristerson L, Lagerstrom L. Autotransplantation of teeth in cases with agenesis or traumatic loss of maxillary incisors. Eur J Orthod. 1991; 13: 486-92.

10. Andreasen JO, Paulsen HU, Yu Z, Bayer T. A longterm study of 370 autotransplanted premolars. Part IV. Root development subsequent to transplantation. Eur J Orthod. 1990; 12: 38-50.

11. Andreasen JO, Borum MK, Jacobsen HL, Andreasen FM. Replantation of 400 avulsed permanent incisors. 2. Factors related to pulpal healing. Endod Dent Traumatol. 1995; 11: 59-68.

12. Kvint S, Lindsten R, Magnusson A, Nilsson $P$, Bjerklin K. Autotransplantation of teeth in 215 patients: A follow-up study. Angle Orthod. 2010; 80: 446-51.

13. Jonsson T, Sigurdsson TJ. Autotransplantation of premolars to premolar sites: A long-term follow-up study of 40 consecutive patients. Am J Orthod Dentofacial Orthop. 2004; 125: 668-75. 